well known but also established. ${ }^{1}$ The lateral popliteal nerve is vulnerable to trauma at the neck of the fibula, but the role of entrapment in unexplained palsies is controversial. Other debatable instances involve the sciatic, obturator, ilioinguinal, and iliohypogastric nerves. ${ }^{2}$ In the welldefined clinical entity, meralgia paraesthetica, burning pain sometimes with numbness occurs in the distribution of the lateral cutaneous nerve of the thigh. Many causes have been suggested, including trusses, military equipment hanging round the waist, intrapelvic anomalies, and intervertebral discs, but usually these are absent and compression of the nerve at the anterior superior iliac spine where it traverses the inguinal ligament is held responsible.

Recently A. V. Applegate ${ }^{3}$ has postulated entrapment of the abdominal cutaneous nerves as a cause of abdominal pain, a diagnostic feature being localization of maximal tenderness to the foramen where the rectus sheath is pierced. Sixty-two patients are described, many of whom had already been extensively investigated for their pain with negative results. Symptoms responded to reassurance alone, locally applied heat or cold, diazepam, or an injection of lignocaine into the appropriate foramen. But there was a tendency to relapse. Unfortunately no details are given about altered cutaneous sensation in the distribution of the affected nerve or of the histology on the one occasion when resection of the nerve was required. Associated disease in $76 \%$ of the patients included diabetes, peptic ulcer, hernia, and depression, which makes it difficult to relate the symptoms entirely to an entrapment phenomenon. The author considers that recognition of the syndrome will prevent unnecessary investigation, but in addition to causes of root pain the differential diagnosis must include disease of the abdominal viscera and urogenital tract and lesions of the abdominal wall such as Spigelian hernia and involvement of cutaneous nerves in operation scars. Pain from the nerve roots may result from intervertebral disc lesions, neurofibroma, meningioma, metastases, or herpes zoster. On the evidence presented so far this idea needs confirmation and should be viewed with the caution afforded some of the other so-called entrapment syndromes.

1 Kopell, H. P., and Thompson, W. A. L., Peripheral Entrapmen Neuropathies, pps.87,101,107, and 113. Baltimore, Williams and Neuropathies,
Wilkins, 1963.

2 Staal, A., in Handbook of Clinical Neurology, ed. P. J. Vinken and G. W. Bruyn, vol. 7, p. 285. Amsterdam, North Holland Publishing Company, 1970.

3 Applegate, W. V., Surgery, 1972, 71, 118.

\section{Carcinoma of Tongue}

Though carcinoma of the tongue is found most commonly in late adult life, it can occur at any age, even in childhood and adolescence. Recently A. G. Pichler and colleagues ${ }^{1}$ reported a case in a 19-year-old boy and collected a further 10 cases occurring within the first two decades of life. C. W. Venables and I. L. Craft ${ }^{2}$ also collected 13 cases of patients with this condition under the age of 30 from the records of the Westminster Hospital radiotherapy department. We should therefore bear in mind that this condition may affect people at any age.

The incidence of carcinoma of the tongue seems to vary in different communities. D. F. Shedd and colleagues ${ }^{3}$ found that the average age-adjusted incidence was 3.3 for men and
0.6 for women per 100,000 population in Connecticut, U.S.A. They compared these figures with those from several other countries and showed that, while there was little change in the incidence of the disease in women, there was considerable variation in men, the lowest incidence being in Sweden (0.6 per 100,000). England fell between them with an incidence of $1 \cdot 4.4$

Carcinoma of the tongue is found most commonly on the lateral border (56\%), but in $23 \%$ it occurs on the posterior third and in $10 \%$ is found on the under surface of the mobile portion of the tongue, where it may be completely hidden from view unless the floor of the mouth is examined. 5 N. Smith 6 has reviewed the diagnostic features of this condition and recommends that all dental and medical examinations of the mouth should include palpation of the tongue. In his review of 17 cases the majority of his patients complained of pain arising in the tongue, which occasionally was of long duration. He had two patients who had no local symptoms at all. The most important clinical diagnostic sign appeared to be induration in the region of the tumour. Usually this was associated with ulceration, and the ulcer commonly had a raised, firm edge. One of the reasons for delay in diagnosis was because treatment was continued for too long with local measures such as adjustment of dentures, removal of teeth, or topical applications, and he recommended that biopsy should be carried out on any ulcer which fails to heal within one week of such treatment.

The prognosis depends on several factors, of which the size and site of the tumour and the presence of metastases appear to be the most important. ${ }^{7}$ Glandular metastases occur most commonly in tumours of the posterior third of the tongue and when the lesion is over $2 \mathrm{~cm}$ in diameter. Once metatases are present the outcome is far worse, the five-year survival rate of patients being then only $18 \%$, whereas patients without them have a five-year survival rate of $72 \% .8$ Since the presence of metastases is related to the size of the primary (metastases occur in $32 \%$ of tumours under $2 \mathrm{~cm}$ diameter and $60 \%$ of tumours over $2 \mathrm{~cm}$ ) the earlier the diagnosis is made the better should be the outcome. R. Flamant and colleagues ${ }^{9}$ in a review of 904 cases found that the mean delay between onset of symptoms and diagnosis was 4.6 months, and $8 \%$ of their patients had had symptoms for over one year. Though it has not been clearly shown that delay in diagnosis affects the ultimate prognosis, ${ }^{2} 10$ it is a reasonable presumption that the earlier it is made the more effectual will treatment be, for the size of the tumour must undoubtedly depend on the length of time it has been present. If we are to improve the outcome of this tragic disease with its attendant morbidity and mortality, we must begin to look for it at earlier stages and particularly before symptoms have developed.

As to the treatment of this condition, most workers still favour irradiation of the local lesion, the most popular method being interstitial irradiation with radium needles. The degree of control obtained depends on the extent of the lesion, but in early cases the local cure rate can be as high as $80 \%$ if these measures are persisted with. ${ }^{5}$ Most of the problems revolve round the treatment of the local lymph glands, and opinion differs on whether they should be removed primarily or only if they contain obvious metatases. A further point of divergence is whether the tumour and glands should be removed en bloc or by two separate operations. At present there would appear to be a good case for prophylactic block dissection of the neck, particularly 
in younger patients, though it must be recognized that frequently this may require a bilateral block dissection, since many of these tumours metastasize to both sides of the neck. One of the common causes of death is recurrence in the cervical region, and E. W. Strong and colleagues ${ }^{11}$ have shown that the rate can be reduced by giving low doses of irradiation before operation. In a controlled trial they found reduction of cervical recurrence rates from $50 \%$ to $31 \%$ when this was done.

1 Pichler, A. G., Williams, J. R., and Moore, J. A., Archives of Otolaryngo$\log y, 1972,95,178$.

2 Venables, C. W., and Craft, I. L., British fournal of Cancer, 1967, 21, 645

${ }^{3}$ Shedd, D. P., Von Essen, C. F., Ferraro, R. H., Connelly, R. R., and Eisenberg, H., Cancer, 1968, 21, 89.

4 Payne, P. M., and Dixon, R. A., South Metropolitan Cancer Registry Bulletin, 1966, No. 4

5 Saxena, V. S., Cancer, 1970, 26, 788.

- Smith, N., Australian Dental fournal, 1968, 13, 333.

7 Wawro, N. W., Babcock, A., and Ellison, L., American fournal of Surgery, $1970,119,455$.

${ }^{8}$ Feind, C. R., and Cole, R. M., American fournal of Surgery, 1968, 116, 482 - Flamant, R., Hayem, M., Lazar, P., and Denoix, P., Cancer, 1964, 17, 377.

10 Sutton, P. R. N., Medical fournal of Australia, 1968, 2, 312.

11 Strong, E. W., et al., Cancer, 1966, 19, 1509.

\section{Gastritis and Gastric Cancer}

About 15,000 people die every year in the United Kingdom from gastric cancer, ${ }^{1}$ but little is known about the causes of the disease. Though it shows a familial incidence, genetic inheritance cannot account for more than a small proportion of that, and while dietary factors are probably of considerable and perhaps paramount importance in causing it epidemiological studies designed to identify them have proved unhelpful. But they have drawn attention to the possibility of causes in the environment by disclosing geographical fluctuations of almost ten-fold between areas of high and low incidence. ${ }^{2}$ Moreover, the risks of contracting the disease vary in migrants to areas with different incidence rates. ${ }^{3}$

The best-known premalignant condition of the stomach is pernicious anaemia. ${ }^{45}$ The risk of gastric cancer is probably four to five times higher in such patients than in the general population. ${ }^{6}$ It has been suggested that this association arises by two pathways, one associated with the increased frequency of blood group $\mathrm{A}$ in patients with either disease, and the other independent, ${ }^{7}$ but it now seems probable that the association is entirely independent of the blood groups. ${ }^{8}$ One possibility is that autoimmune atrophic gastritis is a premalignant condition. But only a minor proportion of patients with gastric cancer prove to have circulating gastric antibodies, ${ }^{9}$ and it would therefore be of considerable interest to know whether the presence of simple chronic superficial or atrophic gastritis increases the risk of later development of gastric cancer.

M. Siurala and his colleagues ${ }^{10}$ found nine gastric cancers in 116 patients with atrophic gastritis diagnosed by gastric biopsy some 10-15 years earlier, and in a recent survey I. R. Walker and his associates ${ }^{11}$ found four gastric cancers in 40 patients found to have "simple" atrophic gastritis from 10 to 22 years earlier. Though exact mathematical comparisons are impossible, these figures are at least equivalent to the risks associated with pernicious anaemia. When the likely frequency of atrophic gastritis in the population is taken into account-as much as $28 \%$ if figures obtained in a normal Finnish population are generally applicable ${ }^{12}$-then atrophic gastritis becomes of greater importance in absolute terms.

Predisposing factors to atrophic gastritis are poorly understood, but a variety of constitutional factors have been suggested, including tobacco smoking and alcohol consumption as well as (weakly) social class. ${ }^{13}$ But there is a far stronger relationship between social class and gastric cancer mortality, with a notably high death rate in the lowest social classes, ${ }^{14}$ a risk which may be increasing rather than diminishing, ${ }^{14} 15$ though changing bases of occupational classification make comparisons difficult. Further investigations of the significance of atrophic gastritis and intestinal metaplasia-also sometimes considered to be a precursor of gastric cancer ${ }^{16}{ }^{17}$ are clearly needed. But it has to be borne in mind that gastric biopsy, a technique which may be simple and trouble-free in experienced hands, is still physically unpleasant for the patient undergoing it.

1 Mortality from Malignant Neoplasms, 1955-65, Part 2. Geneva, World Health Organization, 1970.

Doll, R., Payne, P., and Waterhouse, J. A. H., Cancer Incidence in Five Continents, Vol. i. Berlin, Springer Verlag, 1966.

3 Buell, P., and Dunn, J. E., Cancer (Philadelphia), 1965, 18, 656.

4 Magnus, H. A., Fournal of Clinical Pathology, 1958, 11, 289.

5 Mosbech, J., and Videbaek, A., British Medical fournal, 1950, 2, 390.

6 Blackburn, E. K. et al. International fournal of Cancer, 1968, 3, 163.

7 Hoskins, L. C., Loux, H. A., Britten, A., and Zamcheck, N., New England

Fournal of Medicine, 1965, 273, 633 .
8 Callender, S., Langman, M. J. S., MacLeod, I. N., Mosbech, J., and Rahtkens Nielsen, K., Gut., 197i, 12, 465.

9 Kravetz, R. E.. Van Noorden, S., and Spiro, H. M., Lancet, 1967, 1, 235

10 Siurala, M., Varis, K., and Wiljasalo, M., Scandinavian fournal of Gastroenterology, 1966, 1, 40.

1 Walker, I. R., Strickland, R. G., Ungar, B., and Mackay, I. R., Gut, 1971, 12, 906.

2 Siurala, M., Isokoski, M., Varis, K., and Kekki, M., Scandinavian Fournal of Gastroenterology, 1968, 3, 211 .

${ }^{3}$ Edwards, F. C., and Coghill, N. F., British Medical fournal, 1966, 2, 1409.

14 Registrar General's Decennial Supplement, England and Wales, Occupational Mortality, 1951, part 1. London, H.M.S.O., 1954.

15 Registrar General's Decennial Supplement, England and Wales, Occupational Mortality Tables, 1961. London, H.M.S.O., 1971.

${ }^{16}$ Morson, B. C., British fournal of Cancer, 1955, 9, 377.

17 Siurala, M., Eramaa, E., and Tapiovaara, J., Acta Medica Scandinavica 1959, 164, 431 .

\section{Traumatic Displacement of Fat}

Most of the disabilities and deformities that follow injury are becoming known and well documented, but with the inexorable increase in road traffic accidents and with increasing efficiency in accident services new syndromes are being recognized and reported. Trauma to the hip region in women may cause a rupture of fat tissue with displacement, leaving an ugly lump with an adjacent defect. This condition had not been reported until B. F. Meggitt and J. N. Wilson" described the "battered buttock syndrome," "fat fracture," or "traumatic lipoma" in 12 women, nearly all of whom were injured in car accidents.

The clinical features are not obvious at first because the swelling is large and is mainly due to haematoma. As the bruising becomes absorbed the deformity becomes apparent. There is a large tender mass the size of which is accentuated by the adjacent hollow. Three of the 12 cases reported required operation because the deformity was accompanied by pain and tenderness. At operation the subcutaneous fat was found to have been sheared off the deep fascia, the vertical fibrous septa having been ruptured. In one case an attempt to replace the fat mass was partially successful. In 